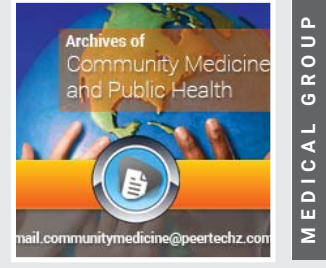

Short Communication

\section{Flu vaccination in children. The pleasant surprise of an indirect positive effect}

\author{
Gaetano Bottaro1*, Giuseppe Bottaro², Filippo Di Forti' and \\ Mara Nicosia ${ }^{3}$ \\ 'Department of Community Medicine, Italian National Health System, Catania Health Authority, \\ Catania, Italy \\ ${ }^{2}$ Department of Cardiology, Policlinico-Vittorio Emanuele Hospital, University of Catania, Catania, Italy \\ ${ }^{3}$ Department of Asia, Africa and Mediterranean Studies, University of Naples “L'Orientale", Italy
}

Received: 20 July, 2020
Accepted: 28 August, 2020
Published: 29 August, 2020

*Corresponding author: Gaetano Bottaro, MD, Department of Community Medicine, Italian National Health System, Catania Health Authority, Catania, Italy, E-mail: gaetano.bottaro@tiscali.it

https://www.peertechz.com

Check for updates
Influence or flu is an infectious disease affecting the upper and lower respiratory tract. It has a high frequency in children, making them a specific target $[1,2]$.

Flu is a serious public health problem and results into very high human and socio-health costs [3]. Seasonal flu epidemics are predictable and, most of all, entirely preventable through vaccination, which, over the years, has proven to be a safe and effective measure $[4,5]$.

Moving to the effects of the flu, the present report will focus on those suffered by children. Important epidemiological studies, carried out in the USA [6,7] and in Spain [8], have clearly shown how, during winter periods, when influenza viruses give rise to classic epidemics, the number of children who gets ill with flu-like forms was higher compared to that of seasons without flu. Only one cohort study has been undertaken on the correlation between the individual child and the short-term protective effect of the flu vaccine on his or her general state of health in the months after the contraction of the disease [9]. Authors attempted to study the impact of flu vaccines on the health of children in the months following the epidemics, therefore typically between January and June, and they have compared these data with that of children who, on the other hand, caught the flu. The placement of a child in the group of "vaccinated" or "sick" children depends on whether the families decided or not to undertake vaccinations on their children. Nevertheless, we provided all the families with the same advice to vaccinate their children, even though not all complied.
The observational and retrospective study was performed at the office of a family pediatrician. The observation involved the comparison between those children who underwent flu vaccination at the pediatrician's office between 2014/15 and 2018/19 ( 5 seasons), and those children who contracted the flu during the very same seasons, as demonstrated by molecular typing of viruses. The molecular typing has been realized within the Epidemiological-Molecular Surveillance Project of the Regione Sicilia by the regional reference laboratory of the Azienda Policlinico "Paolo Giaccone" in Palermo, as described in another paper [9].

The authors collected the data of 657 children, among which 347 were vaccinated and 310 contracted flu. All children were within the age range of 6 months and 14 years old. Concerning the diseases observed beyond rhinitis, which was the most common one, the authors observed that acute otitis media was present only in 41 vaccinated children, against 149 in sick ones; wheezing was similar with 41 episodes in vaccinated children and 101 in sick ones (Figure 1).

As for the frequency of the diseases, we found an average $1.09 \pm 1.25$ episodes in vaccinated children and $2.09 \pm 1.39$ in sick ones (Figure 2). Concerning antibiotic prescriptions, they show the average of $0.40 \pm 0.79$ therapies given to vaccinated children against an average of $0.86 \pm 0.91$ therapies given to sick ones (Figure 2).

Despite certain popular beliefs, influenza is a very dangerous infectious disease. Unfortunately, common feeling has trivialized the term "flu", to the point that today is 


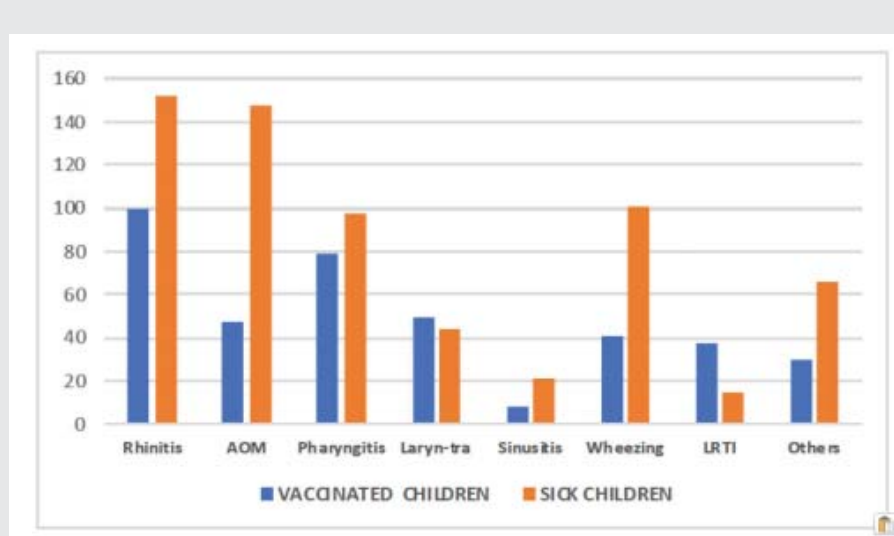

Figure 1: Frequency of the various pathologies in the two groups.

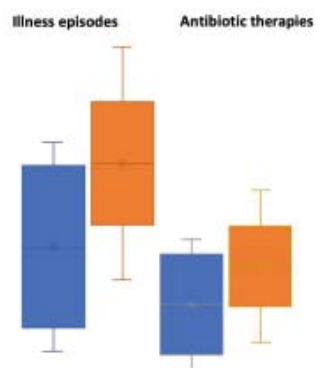

- SICK CHILDREN

- VACCINATED CHILDREN

Vaccinating a child against flu, even if this child is healthy, and does not suffer from any preexisting pathology, proves to be as well an effective way to protect him or her during the months after vaccination. This provides us with a valuable additional weapon of prevention against diseases, the loss of school days, the loss of parents' working days, the excessive use of Emergency, the excessive hospitalizations and, last but not least, results into a reduction of the workload of family pediatricians.

\section{References}

1. Bourgeois FT, Valim C, Wei JC, Mc-Adam AJ, Mandl KD (2006) Influenza and other respiratory virus-related emergency department visits among young children. Pediatrics 118: e1-e8. Link: https://bit.ly/3hBctH5

2. Molinari NA, Ortega-Sanchez IR, Messonnier ML, Thompson WW, Wortley PM, et al. (2007) The annual impact of seasonal influenza in the US: measuring disease burden and costs. Vaccine 25: 5086-5096. Link: https://bit.ly/3gAwxbo

3. Reed C, Chaves SS, Kirley PD, Emerson P, Aragon D, et al. (2015) Estimating Influenza Disease Burden from Population-Based Surveillance Data in the United States. PLoS One 10: e0118369. Link: https://bit.ly/32zFk8i

4. Jain VK, Rivera L, Zaman K, Espos RA, Sirivichayakul C, et al. (2013) Vaccine for Prevention of Mild and Moderate-to-Severe Influenza in Children. N Engl J Med 369: 2481-2491. Link: https://bit.ly/34GwJ6k

5. Grohskopf LA, Sokolow LZ, Broder KR, et al. (2016) Prevention and control of seasonal influenza with vaccines. MMWR Recomm Rep 65: 1-54.

6. Flannery B, Reynolds SB, Blanton L, Santibanez TA, O’Halloran A, et al. (2017) Influenza Vaccine Effectiveness Against Pediatric Deaths: 2010-2014. Pediatrics 139: e20164244. Link: https://bit.ly/3hCC6r5

7. Kwong JC, Buchan SA, Chung H, Campitelli MA, Schwartz KL, et al. (2019) Can routinely collected laboratory and health administrative data be used to assess influenza vaccine effectiveness? Assessing the validity of the Flu and Other Respiratory Viruses Research (FOREVER) Cohort. Vaccine 37: 43924400. Link: https://bit.ly/31ylJ7Z

8. García A, Ortiz de Lejarazu R, Reina J, Callejo D, et al. (2016) Cost-effectiveness analysis of quadrivalent influenza vaccine in Spain. Hum Vaccin Immunother 12: 2269-2277. Link: https://bit.ly/34DS40f

9. Bottaro G, Bottaro G, Palermo F (2020) Flu and Flu Vaccination in Comparison, in the Evaluation of the Health Status of Children. American Journal of Pediatrics 6: 253-258. Link: https://bit.ly/3ltcYoK

10. Pebody RG, Green HK, Andrews N, Boddington NL, Zhao H, et al. (2015) Uptake and impact of vaccination school age children against influenza during a season with circulation of drifted influenza A and B strain, England 2014/15 Euro Surveill 20. Link: https://bit.ly/3b5sVgs

11. Reichert TA, Sugaya N, Fedson DS, Glezen WP, Simonsen L, et al. (2001) The Japanese experience with vaccinating schoolchildren against influenza. $\mathrm{N}$ Engl J Med 344: 889-896. Link: https://bit.ly/3b4sin6

Copyright: @ 2020 Bottaro G, et al. This is an open-access article distributed under the terms of the Creative Commons Attribution License, which permits unrestricted use, distribution, and reproduction in any medium, provided the original author and source are credited. 